\title{
Economic Development and Higher Education
}

\author{
Kavita A. Sharma \\ Former President, South Asian University, Akbar Bhawan, Chanakyapuri, New Delhi - 110021, \\ India; kavi.noida10@gmail.com
}

\section{Introduction}

In India, there has been a massive expansion of higher education after independence, making it the third largest higher education system in the world after USA and China, but it is still very inadequate in terms of access, equity and quality. Currently, it provides access to around 27 per cent of the relevant population, and efforts are being made to increase it to about 30 per cent the level required for a mid-level economy. The relationship between higher education and economic development has been established the world over leading to the "massification" of higher education and moving towards its universalization. This has linked it firmly to employability raising questions about relevance and quality of higher education. The need to simultaneously expand to increase access and create equity, while simultaneously tackle the issues of relevance and quality by upgrading existing institutions has put a strain on the resources available for public funding of higher education. This has led to the emergence of the private sector in higher education that has prioritized subjects like engineering, medicine, management, media, law, applied sciences and technology together with subjects related to the service industry and skill development. Social sciences and humanities are facing neglect which gets emphasized as higher education moves to the private sector. Further, there is an acute need for research for knowledge formation and its dissemination in which boundaries between disciplines get blurred. All this means that the way we think of the organization, financing, governance structures and delivery systems of higher education has to be revisited with regard to state funded institutions and the emergence of the private sector which has grown while policy for it has lagged behind. 1

In India, the strains in the system are more than evident as there are only a few research universities at the top and the bottom does not adequately fulfill the requirements of demand. Therefore there little time to devote to relevance and quality. The skill formation is inadequate and too dysfunctional to meet the requirements of a growing and diversifying economy. While IITs and IIMs may be internationally competitive, they are only niche institutions which cater to a very small percentage of student population. One of the fundamental causes of malaise is, perhaps, what Prof. Altbach points out when he says that the mass of institutions of higher education have no clarity of vision about their purpose and aim. The universities are neither provided resources nor do they have the mandate to build a distinctive and innovative profile which is essential for successful academic systems. Consequently, they continue as an undifferentiated mass repetitively producing more of the same. If there was clarity on what different institutions are attempting to deliver, then their funding sources and patterns could also be diversified. $\underline{\text { ? }}$

The accountability in the system is so diffuse and distributed that no one can be held responsible for delivery and outcomes. This leads to mediocrity. It is only natural because most academic arrangements in India have been derived from British colonialism and were not meant to be effective or encourage quality. The most affected is undergraduate education as the affiliating system puts the undergraduate colleges under the universities with their highly bureaucratized and controlled environment. It impedes innovation as they have to follow the common centralized policies without any autonomy. The universities, in turn, receive their funding from the government. Hence, while they have formal autonomy, they too are basically under the control of central or state governments. Also, they have been politicized which makes them ideologically blinkered and contentious. All this has made issues of quality assurance very ambiguous. 


\section{Issues of Development}

Up to the end of the Second World War, development was largely associated with the West and was assumed to be concomitant with modernization. It was linked to economic growth measured in terms of GNP and other similar paradigms. There was an underlying assumption that modernization and economic development had a homogenizing effect and produced a common modern culture closely resembling that which has existed in the West in the twentieth century. In the contemporary world, most modern societies have been Western societies. While modern, urban, literate, wealthy and industrialized societies share cultural traits that distinguish them from backward, rural, poor and undeveloped societies, modernization does not equal westernization.

There has been an obvious discontent with the conventional theory and practice of development that has led to the growth of new social movements which paved the way for the idea of sustainable development. Sustainable development was a shift away from the narrow concerns of mainstream economics and modernization theories that emphasize economic growth to the disregard of other concerns like relationship between ecology, inter and intra generational equity, and social justice.

However, there is unease over sustainable development too because there is also a view that the mainstream notion of sustainable development still prioritizes capital accumulation and concepts of growth and efficiency. It only "limits the growth" but its ideas of development continue to rest on the tenets of Western technological civilization. Environmental concerns are pivotal to it but increasingly an interface is needed between environment, economic and social sustainability. In order to do this effectively, a new vocabulary of development must possibly arise out of the civilizational cultural values. For this, culture would have to be seen as an intrinsic part of development and a basis for interrogating the meaning and practice of sustainable development. Peoples' identities, signifying systems, cosmologies and epistemic frameworks shape how the environment is viewed and lived in. This is their culture, in effect, their whole way of life and belief system.

If civilizational and cultural values are placed at the centre of the development discourse, it will alter its social, political and technological context. Development cannot be then viewed merely as a process of growthoriented industrialization. An alternative approach would prioritize at least four factors. One is cultural identity. In that case, the social unit of development would be a cultural community and the development of this community would be rooted in the specific values and institutions of this culture. Second, each community would be self-reliant standing primarily on its own strength and weaknesses. Third, its development efforts would necessarily prioritize those who are the most needy in that community. Finally, it would be fully aware of the potential of local ecosystems as well as the global and local limits imposed on present and future generations. In effect, it would mean that a country like India with its strong cultural heritage, would have the option to examine indigenous solutions together with the Western ones rather than axiomatically accept western solutions as the only model of sustainable development.

The above formulation leads to certain questions. What is the kind of research that universities need to do, whether public or private and to what end? What are the forces that drive this research? Has the kind of research being pursued led to imbalances in the outcomes and the privileging of some disciplines over others? What are the consequences of this and impact on society at large?

A large part of the renewed enthusiasm for higher education and research stems from the motivation that it will lead to higher and higher rates of economic growth and more and more income for individuals who can use the new technologies. However, unacceptable levels of disparity have been created because research efforts are unevenly distributed between different countries and regions. As has been pointed out, it is only a few industrialized countries that conduct the greater part of world's research. This is problematic for developing countries who do not have the means or the education base to get a large share in the global research effort. Quite inevitably, most of the research effort is directed at problems and questions that are related to the needs of industrialized countries where the research is conducted. Applied to developing countries, their solutions may not be appropriate. Also, developing countries may not even have the level of competency in education, research and technology that is required to benefit from the knowledge developed elsewhere.

Therefore, if the fruits of research have to reach the developing countries, developed countries must also increase research funding for problems of those countries that do not have the capacity to invest much in research. There is a growing awareness internationally of the need to enhance the role of higher education, by 
embedding it as part of aid and development policies. Of course, there is no equal correlation between benefits of research and the efforts required to be put into research. It is not necessary for countries to necessarily share in the costs of developing technology to partake of its benefits. The development of new technology may be costly but the price of using it may be low. However, even to use the available technology, there has to be a broad knowledge base and therefore higher education is important.

The way research endeavors have grown, it has led to the privileging of science, but is this the surest route to development, or is there a need to also incorporate other routes? Development is a practical end sought to be achieved through research and its applications but the universalistic scientific approach without factoring in the national, social and cultural dimensions, can lead to problematic and even tragic results. Therefore, scientific endeavors have to be linked to social concerns and scientists need to be aware of the societal impact of their work, before their research and its applications bring collective well-being and equity in society and salvage the Earth's environment.

Science is only a part of a richer whole and spaces have to be created to bring scientists and different audiences together in democratic spaces so that expert knowledge can become comprehensible and more widespread. This would enable plural perspectives to emerge on the pros and cons of application and increase informed awareness among citizens. Without it, the growth of higher education will not necessarily reduce social and economic inequalities and may even widen the gulf. These disparities can develop both domestically within nations and internationally among different nation states. The process of linking higher education especially-science and technology with economic growth started with the move towards open market policies in the 1970s when greater emphasis was given to growth than to income distribution and social objectives. This was the wisdom of North America and the OECD countries, and finally it was followed by the whole world.

This has led to asymmetries based on the economic capacities of different countries. While education, knowledge and research base of science has increased mainly in developed countries, the same has not happened in the developing world. This is because of lack of resources as research is resource intensive and allocation of resources have to be balanced between increasing access while simultaneously improving the quality of teaching-learning processes.

It leads to the conclusion that higher education and science have to be more evenly distributed around the world. Also, most of the developing countries and the least developed countries are the erstwhile colonized countries. They have not yet recovered from the ravages of colonization culturally, societally and in terms of development. Therefore, universities cannot just do research that is neutral. While research in science is the way forward, universities have to also contribute to building foundations of civic and democratic values for social cohesion. They must create knowledge that not only leads to economic growth but also to an understanding of how to overcome racial and ethnic tensions, dogmatism and religious extremism that often come with uneven growth and uneven distribution of fruits. This requires immediate attention to cultural diversity in higher education and research within the framework of globalization. This does not mean merely increasing the population of the underrepresented social groups in a campus population. It means building knowledge systems that give an understanding of diverse values, policies, practices, traditions, resources and living knowledge systems outside the formal structures so that students, faculty and communities that have been excluded up to now can become part of the knowledge resource and provide keys and solutions that have eluded thought and policy.

This brings us to what, Mahmood Mamdani ${ }^{\frac{3}{3}}$ speaking in the context of Africa says, the central issue is that we are still dealing in the framework of the Western paradigms derived from the values of Enlightenment, whether we extol its virtues or critique it. However, as he points out, while it may be vital to understand Enlightenment, it is an exclusively European phenomenon, that excludes Africa. By the same token it also excludes Asia. Hence, the central question is whether universities in Africa and Asia can be founded on those values.

The implication of exclusively following the Enlightenment framework is, as Mamdani points out, that it presents a single model derived from the dominant Western experience and reduces research to a mere demonstration of whether societies around the world conform to that model or deviate from it. This has to be challenged because discordant experiences, whether Western or non-Western, cannot be de-historicized or de-contextualized to somehow make them fit into the dominant Western experience. ${ }^{4}$ 


\section{The Indigenous Potential}

This is perhaps the mission of Anil K Gupta from IIM Ahmadabad with his honey comb initiative. $\mathrm{s}$ He has challenged the dominant developmental paradigm in which the role of the state or civil society is only to provide what poor people lack i.e., material resources, opportunities for gains in skills or employment. Strategies of development do not build upon a resource in which the poor people are often rich; it is the knowledge that they possess. They are not 'resource poor people' simply because they do not have material wealth. Their resource is their knowledge and it has enabled them to innovate and survive, particularly in high risk environments. It involves "the blending of the secular with the sacred, reductionism with holism, short-term options with long-term ones, specialized with diversified strategies in individual or collective material, or in non-material pursuits." This is reflected in the environmental ethics of these communities. Writing and working consistently on this area for over two decades, Gupta points out that when there is physical, technological, market or socio-economic stress, the disadvantaged communities inevitably generate innovative and creative alternatives for resource use. The innovations may originate in both tradition and in modern awareness. They may be evolved by communities or by individuals. Usually, it is the joint endeavor of communities and this may have led to the widespread indifference towards the entrepreneurial potential of the knowledge rich but economically poor people. Therefore, what is 'relevant' research would be different in different domains and yet all must form an integrated ecosystem. It would have to take in both the local and the global to form a continuous whole, and teaching would have to be organized accordingly. Seen thus, teaching and research would be a continuum.

\section{Conclusion}

The Indian education system is vast but fragmented in which different sectors have little or no conversation with each other. For example, there is no 'awareness bridge' between the school system, institutions of higher education, research institutions, vocational training and skill development and professional education. This lack of dialogue is also very evident in the various sectors in which educational institutions function-private, public and public private partnerships. In fact, there often seems to be hostility between them. Each works in isolation and often at cross purposes and so is neither able to capitalize on its individual strengths nor can it collaborate with others. The sufferers are the students and the quality of education they receive. The research is under-funded and the lack of collaboration means that the strengths of various institutions cannot come together to make a mark internationally except in some niche areas. Hence, the results are for all to see in every sphere.

Right now, Indian higher education seems to be stuck in a quagmire. If it has to meet the challenges, it has to systematically create an internationally competitive academic system. For this, it will have to rise above ideological biases and politics to reform its outmoded structures of academic governance and delivery system and build a national consensus by a continuous centerstate dialogue on higher education both in the public and the private sectors. A tall order perhaps, but without it the Indian higher education system can neither deliver nationally nor can it compete globally.

\section{References}

1. Parts of this article form a part of my larger work, Kavita A Sharma, Perspectives on Indian Education, Delhi:Gyan Publishing House, 2017.

2. Altback, Philip G. "Tiny at the Top," "A World-Class Country Without World-Class Education," "India's $21^{\text {st }}$. Century Dilemma," “The Giants Awake: Higher Education Systems in China and India," "A Half-Century of Indian Higher Education," Essays by Philip Altbach, Pawan Agarwal ed., New Delhi:Sage Publishers.

3. Mahmood Mamdani. "The Importance of Research in a University,"www.pambezuba.org/resources/importanceresearch-university

4. Ibid.

5. Anil K. Gupta. "Honey Bee Network," www.sristi.org/ cons/?q=en/book/print/519 This article summarizes the essential vision that has motivated Gupta in the structures he has established to encourage and mainstream the grassroots knowledge and innovation. See also, Anil K. Gupta, Grass Roots Innovation: Minds on the Margins are not Marginal Minds, Deli:Random House, 2016. 